\title{
(RE)Pensando o espaço público democrático: o fato do pluralismo e a ideia de tolerância na concepção política de justiça de John Rawls
}

(RE) Thinking democratic public space: the fact of pluralism the idea of tolerance in John Rawls's political conception of justice

\begin{abstract}
Anna Paula Bagetti Zeifert Doutora em Filosofia PUCRS. Professora do Programa de Pós-Graduação - Mestrado e Doutorado em Direito - e do Curso de Graduação em Direito da UNIJUÍ. Integrante do Grupo de Pesquisa Direitos Humanos, Justiça Social e Sustentabilidade anna.paula@unijui.edu.br

(iD) Joice Graciele Nielsson Doutora em Direito UNISINOS. Professora do Programa de Pós-Graduação - Mestrado e Doutorado em Direito - e do Curso de Graduação em Direito da UNIJUÍ. Integrante do Grupo de Pesquisa Biopolítica e Direitos Humanos joice.nielsson@unijui.edu.br
\end{abstract}

Resumo: O presente artigo tem por objetivo analisar o processo de construção de um espaço público democrático, a partir da teoria de justiça política de John Rawls, demonstrando como a prática pública da justiça, enquanto valor social compartilhado auxilia no estabelecimento de uma sociedade mais justa, capaz de enfrentar o fato do pluralismo e promover a tolerância, criando os meios para uma discussão política razoável em torno da justiça. Demonstra a relevância da liberdade para a consecução da prática pública da justiça como valor social democrático, e posteriormente os elementos do pluralismo e da tolerância, como fundamentais desde o princípio na sua proposta à concepção de justiça que comportaria uma visão plural de sociedade. Para seu delineamento utiliza o método de abordagem hipotético-dedutivo, centrado em autores contemporâneos da filosofia política.

Palavras-Chave: Democracia. Justiça. Pluralismo. Tolerância.

Abstract: This article aims to analyze the process of building a democratic public space, based on John Rawls's theory of political justice, demonstrating how the public practice of justice, as a shared social value, helps to establish a fairer society capable of to confront the fact of pluralism and promote tolerance by creating the means for a reasonable political discussion around justice. It demonstrates the relevance of freedom to the attainment of the public practice of justice as a democratic social value, and later the elements of pluralism and tolerance, as fundamental from the outset in its proposal to the conception of justice that would include a plural view of society. For its design it uses the hypothetical-deductive approach method, centered on contemporary authors of political philosophy.

Keywords: Democracy. Justice. Pluralism. Tolerance. 


\section{Introdução}

Analisar a noção de democracia e tolerância em Rawls necessariamente exige compreender as diretrizes do projeto rawlsiano de justiça social, a construção dos princípios de justiça como forma de garantir liberdade e igualdade, bem como estabelecer as bases do respeito e tratamento equitativo em uma sociedade justa e bem ordenada. Em épocas como as atuais, nas quais a proposição de um projeto de existência coletiva é posta em questão, por diversas formas de pensamento que corroem a ideia de justiça democrática, empreender este exercício parece ser cada dia mais relevante e necessário.

Sendo assim, o presente artigo tem como objetivo demonstrar como a prática pública da justiça, enquanto valor social compartilhado auxilia no estabelecimento de uma sociedade mais justa, capaz de enfrentar o fato do pluralismo e promover a tolerância, criando os meios para uma discussão política razoável em torno da justiça. Em A Theory (1999), o autor propõe possibilidades de conciliação entre essas diferentes concepções de bem, pois entende que os sujeitos em uma sociedade complexa não compartilham de uma única concepção de bem, mas de diferentes e, assim, os planos de vida são os mais variados possíveis. É nesse contexto de organização dos projetos de vida individuais que Rawls está observando a melhor maneira de estabelecer um ponto em comum capaz de identificar e unir os sujeitos. (LOVETT, 2013)

Faz parte do entendimento rawlsiano o fato de que essa unidade enfrenta vários desafios, principalmente porque é necessário que os cidadãos efetivamente aceitem um projeto de justiça social e compreendam que esse pode conviver pacificamente com suas concepções de bem, ou pelo menos, com aquelas que evitam o radicalismo. Porém, Rawls precisa ir mais a fundo para que essa proposta de justiça como equidade se torne parte da vida pública. Necessita tornar forte o sentido da justiça em cada sujeito a fim de que no embate entre uma concepção de bem não razoável, a justiça, ou melhor, os princípios de justiça, prevaleçam e passem a servir de guia para a instauração da justiça social. Nas palavras de Lovett (2013, p. 117, grifo do autor), "não é suficiente que os cidadãos tenham meramente um desejo de promover a justiça se esse desejo não for forte o bastante para regular os seus planos de vida."

O senso de justiça em cada cidadão deve ser necessariamente sólido, resistir a qualquer obstáculo ou afronte, garantindo o projeto social adequado no interior de uma sociedade que tem como objetivo ser bem ordenada. Esse senso de justiça forte viabiliza a estabilidade e, consequentemente, a justiça como equidade enquanto teoria que prima pela cooperação, fundamento da justiça política rawlsiana. Como essas possibilidades de estabilidade social 
(RE)Pensando o espaço público democrático: o fato do pluralismo e a ideia de tolerância na concepção política de justiça de John Rawls

foram trabalhadas em Theory (1999), observamos a influência kantiana na teoria rawlsiana ${ }^{1}$, no entanto, com o passar do tempo, Rawls revisa este modelo de estabilidade por entender que o mesmo poderia induzir ao erro quem pretendesse utilizá-lo como forma de medir o grau de solidez de uma sociedade com relação à justiça social. Outra situação que deve ser considerada é o fato de que a concepção do bem formulada e passada de geração para geração pode facilmente ser uma doutrina moral que no interior se apresenta inteiramente contraditória com a realidade social.

Por tais razões é que Rawls, nas reformulações, opta por adotar as expressões "consenso sobreposto" e "doutrinas morais abrangentes" como forma de melhor explicar e embasar a sua teoria da justiça como equidade, bem como uma noção inteiramente nova de estabilidade tendo como referência a ideia de pluralismo razoável. ${ }^{2}$

\section{A justiça como valor social democrático e a relevância da liberdade}

A concepção rawlsiana de justiça, constituída a partir do consenso sobreposto guarda uma intrínseca relação com a democracia. Mais do que isso, sua justiça política apenas é possível no interior de uma sociedade democrática, não sendo viável um consenso ligado à ideia de comunidade política. Há, em Rawls, uma diferenciação fundamental entre as concepções de comunidade e sociedade. Embora o autor tenha destacado em Theory (1999), que a prática pública da justiça é um valor comunitário, em suas obras posteriores a prática pública da justiça torna-se um valor social. Como bem elucida em Political Liberalism (§7):

Uma sociedade democrática bem-ordenada não é uma comunidade, nem, em termos gerais, uma associação. A primeira é que supusemos que uma sociedade democrática, como qualquer sociedade política, deve ser vista como um sistema social completo e fechado. É completo no sentido de ser auto-suficiente e de ter espaço para todos os principais objetivos da vida. Também é fechada [...], no sentido de que só se entra nela pelo nascimento e só se sai dela pela morte. Não temos uma identidade anterior à nossa entrada na sociedade: não é como se viéssemos de outro lugar; encontramonos crescendo em tal sociedade e em tal posição social, com suas correspondentes vantagens e desvantagens, como quis nossa boa ou má sorte. Assim sendo, a percepção não é a de que entramos na sociedade na idade da razão, como o faríamos

\footnotetext{
${ }^{1}$ Em sua obra, o autor passa a questionar os caminhos escolhidos por Rawls para desenvolver a sua teoria e a sua própria ideia de justiça. Segundo Ricoeur, existiriam duas razões para sua escolha, a primeira é que Rawls "[...] situa-se mais na descendência de Kant que de Aristóteles." Para Aristóteles a teoria da justiça deveria ser compreendida "[...] como uma virtude particular a saber, a justiça distributiva e corretiva tira o seu sentido, como todas as outras virtudes, do quadro teleológico do pensamento que a coloca em relação com o bem, pelo menos tal como é compreendido pelos seres humanos;" Já em Kant, diferente de Aristóteles, "verifica-se uma inversão de prioridade em benefício do que é justo e em detrimento do que é bom, de tal modo que a justiça ganha sentido num quadro deontológico de pensamento.” Já a segunda razão, visa esclarecer que "enquanto em Kant a ideia de justiça aplica-se antes de mais às relações de pessoa a pessoa, com Rawls a justiça aplica-se prioritariamente às instituições - é a virtude por excelência das instituições - e somente a título secundário aos indivíduos e aos estados-nação considerados como indivíduos no palco da história." (RICOEUR, 1995, grifo do autor)

2 "A Teoria da justiça como equidade procuraria reconciliar ou pacificar as sociedade pluralistas apresentando os princípios de justiça aos quais os cidadãos devem se submeter. Esses princípios seriam puramente 'políticos' ou seja, não colocariam em questão suas crenças pessoais. Não tendo nenhuma pretensão à verdade, esses princípios não poderiam entrar em choque com a fé religiosa, as opiniões morais e as filiações dos cidadãos." (AUDARD, 2006, p. 11)

210
}

Prisma Jur., São Paulo, v. 18, n. 2, p. 208-223, jul./dez. 2019 
no caso de uma associação, mas a de que nascemos numa sociedade onde passaremos toda a vida. (RAWLS, 2000, p. 84),

Tomando por base sociedades democráticas, Rawls (2000, p. 91) estabelece o seguinte questionamento: "Como é possível existir, ao longo do tempo, uma sociedade justa e estável de cidadãos livres e iguais que se mantêm profundamente divididos por doutrinas religiosas, filosóficas e morais razoáveis?" e na sua própria tentativa de formular as respostas, apresenta como fundamentais ao seu empreendimento teórico, a relação entre a ideia de liberdade, presente no primeiro princípio $^{3}$, de pluralismo razoável e da tolerância.

As liberdades fundamentais expressas no primeiro princípio de justiça, e que representam parte da lista de bens primários, garantem a prioridade do primeiro princípio em relação ao segundo. Uma lista de bens primários é trabalhada por Rawls na sua obra Political Liberalism (1993), conforme analisa Weber (2013), esse rol de bens primários comportaria: (a) os direitos e liberdades fundamentais, que incluem, entre outros, a liberdade de pensamento, de consciência, de associação, de expressão, de participação política, de propriedade. Trata-se de 'condições institucionais essenciais' para o desenvolvimento das qualidades morais; é o mínimo existencial no sentido restrito; b) 'as liberdades de movimento e livre escolha de ocupação' diante da diversidade de oportunidades; c) 'os poderes e prerrogativas de cargos e posições de responsabilidade'; d) 'renda e riqueza', que incluem recursos materiais necessários para atingir minimamente os inúmeros objetivos, bem como realizar as faculdades morais; e) "as bases sociais do autorespeito (self-respect)'.

Isso se deve ao fato de que certas liberdades possuem relação direta com a estrutura básica da sociedade, dentre elas, destacamos as seguintes: liberdade de consciência, que, por sua vez, se vincula à liberdade de pensamento e à liberdade de associação, e liberdades políticas iguais. Conforme o Rawls (2000, p. 386-387),

A garantia do valor equitativo para as liberdades políticas é incluída no primeiro princípio de justiça porque resulta essencial para estabelecer uma legislação justa e também para assegurar que o processo político equitativo especificado pela constituição esteja aberto a todos numa base de igualdade aproximada. A ideia é incorporar à estrutura básica da sociedade um procedimento político efetivo que espelhe nessa estrutura a representação equitativa de pessoas alcançada na posição original. É a eqüidade desse procedimento, assegurada pela garantia do valor eqüitativo das liberdades políticas, e justamente com o segundo princípio de justiça (e com o princípio de diferença), que oferece a resposta à pergunta de por que as liberdades fundamentais não são puramente formais.

\footnotetext{
${ }^{3}$ Como primeiro princípio Rawls $(2002,64)$ defende que "cada pessoa deve ter um direito igual ao mais abrangente sistema de liberdades básicas iguais que sejam compatíveis com um sistema de liberdade para as outras." O princípio utilizado aqui é o apresentado em A Theory of Justice de 1971, sem as reformulações posteriores.
} 
(RE)Pensando o espaço público democrático: o fato do pluralismo e a ideia de tolerância na concepção política de justiça de John Rawls

Existe, nesse sentido, uma ligação direta entre tais liberdades e a concepção de pessoa pressuposta por Rawls (2000) e que irá influenciar as partes na escolha dos princípios. Mesmo não tendo plena certeza de que as pessoas que representam professam as mesmas concepções de bem que agora estão a influenciar na escolha das liberdades fundamentais presentes nos princípios, as partes devem intuir que as pessoas as façam.

Nesses termos, a liberdade de consciência, na condição de possuidora de um grau de prioridade ante as demais liberdades fundamentais, reflete a possibilidade de ser livre para professar uma concepção de bem, ou seja, de “[...] formar, revisar e procurar realizar racionalmente uma determinada concepção do bem." (RAWLS, 2000, p. 367), e poder revisála quando for necessário, posto que esta representa um meio para o bem de uma pessoa. Nesse mesmo sentido, aparece a liberdade de associação, que possibilita ao indivíduo se unir a outro indivíduo a fim de que possam compartilhar uma concepção de bem.

Portanto, ter senso de justiça inspiraria as partes a buscar princípios que garantam a liberdade. Na posição original quando as partes, na qualidade de "representantes racionalmente autônomos" das pessoas, favoreceriam as concepções de bem endossadas pelas mesmas. Para tanto, resta claro que a concepção do bem que deverá inspirar as partes e que será aceita como razoável, é aquela que garante a observância e a prioridade das liberdades fundamentais. No entender de Rawls (2000), o senso de justiça que irá influenciar as partes na adoção dos princípios de justiça viabiliza e garante a prioridade de certas liberdades fundamentais, liberdades essas que teriam como tarefa primordial apoiar o autorrespeito.

Conforme descreve Rawls (2000, p. 374), “o auto-respeito baseia-se em nossa autoconfiança enquanto membros plenamente cooperativos da sociedade, capazes de tentar realizar uma concepção do bem merecedora de respeito ao longo de toda a vida”. Assim, o autorrespeito "pressupõe o desenvolvimento e exercício de ambas as capacidades morais e, por isso, um senso de justiça efetivo. A importância do auto-respeito é que ele proporciona um sentimento seguro do próprio valor, uma convicção firme de que vale a pena procurar realizar nossa própria concepção do bem". De tal modo, sem auto respeito, nada valeria a pena, e mesmo que algumas coisas possam ter valor para cada um de nós, não temos vontade de buscar sua realização. "Desse modo, as partes dão grande peso ao grau de eficiência com que os princípios de justiça dão sustentação ao auto-respeito, pois, caso contrário, esses princípios não podem promover efetivamente as concepções determinadas do bem daqueles que as partes representam" (RAWLS, 2000, p. 374). A partir desta caracterização de autorrespeito, o autor afirma que ele "depende de, e é incentivado por, certas características públicas de instituições 
sociais básicas, de como elas funcionam juntas e de como se espera que as pessoas que aceitam esses arranjos considerem e tratem umas às outras" (idem). Essas características das instituições básicas são as bases sociais do autorrespeito.

Nesse contexto, ao expressarem publicamente a defesa das liberdades fundamentais em uma sociedade bem ordenada, os cidadãos manifestam o seu respeito mútuo com todos os demais cidadãos, como sujeitos livres e iguais, razoáveis e racionais, bem como valorizam todas as formas de vivências possíveis no interior da ordem social democrática. Para Rawls (2003. p. 273), pessoas razoáveis "estão dispostas a propor certos princípios (que definam termos equitativos de cooperação), bem como a concordar com esses princípios mesmo a expensas de seus próprios interesses se as circunstâncias o exigirem", e considerando que os outros tenham a mesma disposição. Deste modo, quando as reivindicações daqueles "que cooperam têm bases semelhantes nos aspectos relevantes, bem como quando todos têm o status de cidadãos livres e iguais, não há motivos para que nenhum deles aceite princípios que lhes atribuam menos direitos básicos que o resto". Aqueles que "insistem em impor tais princípios sobre os outros, motivados, digamos, por seu maior poder ou posição de barganha mais forte, não estão sendo razoáveis, embora, dados os seus interesses, possam ser perfeitamente racionais". Portanto, a fala cotidiana reflete esse contraste entre o razoável e o racional.

Assim, estaria fundamentada a chamada "união social", um bem mais abrangente que o bem individualmente estabelecido, um bem que comporta o bem específico construído pelos indivíduos que compõem a sociedade. Sobre esta questão, Sá (2008, p. 10), relembra que para Rawls, "a sociedade política não se pode constituir em função de um fim particular ou, o que é o mesmo, em torno de um conceito de bem em referência do qual as suas instituições fundamentais se poderiam determinar como justas ou injustas". Deste modo, prossegue uma sociedade liberal, na medida em que se coloca como "uma sociedade estruturalmente pluralista, não pode deixar de rejeitar qualquer concepção que procure fundamentar o que é justo numa intuição prévia daquilo que é bom", pois, "é exatamente na consideração do que seja bom que uma sociedade estruturalmente dividida por várias doutrinas compreensivas não pode encontrar consenso"

Portanto, os princípios de justiça teriam a tarefa de estabelecer o bem mais abrangente que combinaria na sua essência as muitas concepções de bem. Como o próprio autor manifesta, “seria a combinação de muitas uniões sociais em uma união social” (RAWLS, 2000, p. 378).

\footnotetext{
${ }^{4}$ Cabe lembrar, de acordo com Sá (2008, p. 10), que "É esta dificuldade que Rawls assinala a uma perspectiva utilitarista do liberalismo. Se a sociedade se constituísse em função de um fim qualquer, mesmo que esse fim fosse 'a utilidade no sentido mais vasto, fundada nos interesses permanentes do homem enquanto ser progressivo' tal como o define Stuart Mill, ela excluiria necessariamente a possibilidade de outros fins concorrentes e, consequentemente, nunca seria senão acidentalmente tolerante"
} 
Eis aí a primeira resposta à pergunta feita no início deste artigo: Como promover a justiça em uma sociedade composta pelas mais diversas doutrinas morais abrangentes?

Como se depreende desta formulação, o objetivo da proposta rawlsiana é que as liberdades fundamentais presentes nos princípios de justiça sejam reconhecidas publicamente, tanto por indivíduos particulares quanto pelas associações que compõem a sociedade democrática, e que faça parte da união social como um bem mais abrangente. É uma espécie de acomodação das várias doutrinas morais professadas, de maneira a estabelecer, em consenso, liberdades fundamentais que viabilizariam uma "vida digna" para todos os indivíduos. Rawls (2000) no entanto, compreende as dificuldades que existem nas sociedades e que afetam significativamente a efetividade de muitos direitos e a plenitude do valor liberdade, que poderá ter seus benefícios reduzidos em razão dos obstáculos para o seu exercício. Para elucidar, Rawls (2000, p. 381) aduz que

\begin{abstract}
Muitos argumentam, principalmente os democratas radicais e os socialistas, que, embora possa parecer que os cidadãos são efetivamente iguais, são demasiado grandes as desigualdades sociais e econômicas que provavelmente surgirão, se a estrutura básica incluir as liberdades fundamentais e a igualdade equitativas de oportunidades. Aqueles com maior responsabilidade e riqueza podem controlar a elaboração legislativa em benefício próprio. Para responder a essa questão, vamos distinguir entre as liberdades fundamentais e o valor dessas liberdades, da seguinte forma: as liberdades fundamentais são especificadas por direitos e deveres institucionais que permitem aos cidadãos fazer várias coisas, se o desejarem, e que proíbem outros de interferir nisso. Elas constituem um quadro de referência das vias de ação e das oportunidades legalmente protegidas.
\end{abstract}

Deste modo, a justiça como equidade não é indiferente a injustiça social, ao contrário, busca romper com a lógica de exclusão social a partir do segundo princípio de justiça ${ }^{5}$, quando as liberdades relativas ao bem-estar de cada um dos indivíduos integrantes da sociedade são evidenciadas. São os bens primários referentes à renda e à riqueza, compreendidos como "meios materiais polivalentes para os cidadãos promoverem seus fins dentro do quadro de liberdades iguais e igualdade equitativa de oportunidades" (RAWLS, 2000, p. 382), que romperam com os obstáculos impostos pela desigualdade social.

Portanto, afirma Rawls (2000, p. 382), “as liberdades políticas iguais e a liberdade de pensamento devem assegurar a aplicação livre e bem-informada dos princípios de justiça, por meio do exercício pleno e efetivo do senso de justiça dos cidadãos, à estrutura básica da sociedade", lembrando que, segundo o autor as liberdades políticas, garantido seu valor equitativo, e outros princípios gerais relevantes, podem, evidentemente, suplementar os

\footnotetext{
${ }^{5} \mathrm{O}$ segundo princípio, afirma que "as desigualdades sociais e econômicas devem ser ordenadas de tal modo que sejam ao mesmo tempo: (a) consideradas como vantajosas para todos dentro dos limites do razoável (princípio da diferença), e (b) vinculadas a posições e cargos acessíveis a todos." (RAWLS, 2002, 64)

214
}

Prisma Jur., São Paulo, v. 18, n. 2, p. 208-223, jul./dez. 2019 
princípios de justiça. Assim, "essas liberdades fundamentais requerem uma dada forma de regime democrático representativo e as necessárias proteções à liberdade de expressão política, de imprensa, liberdades de reunião e congêneres". Cabendo à liberdade de consciência e a liberdade de associação a tarefa de assegurar a "aplicação plena, bem-informada e efetiva das faculdades da razão deliberativa dos cidadãos para a formação, revisão e busca racional da realização de uma concepção do bem ao longo de toda a vida"

Nesse sentido, para Rawls (2000) a sua proposta é desafiadora em razão de que terá de lidar com os grandes desafios da humanidade, objetos de lutas e desavenças, e as quais remetem à atualidade conflituosa da institucionalidade brasileira: as questões relacionadas às crenças religiosas, doutrinas filosóficas e as mais variadas concepções de bem, que produzem profundas desavenças no interior de uma sociedade. $\mathrm{O}$ autor pretende estabelecer um acordo justo que possa unir e, assim, criar uma nova forma de cooperação.

\section{Pluralismo e a tolerância nas sociedades democráticas}

A partir do exposto anteriormente, e tendo em vista o propósito da proposta teórica rawlsiana, é possível deduzir que duas questões são fundamentais desde o princípio na sua proposta: à concepção de justiça que comportaria essa visão plural de sociedade e a de tolerância. A primeira questão evidencia que a concepção de justiça rawlsiana é política e não metafísica.

Evidenciada esta questão, interessa averiguar como a tolerância aparece inserida na proposta de justiça como equidade e o seu papel como agente estabilizador. Para tanto, tomaremos como ponto de partida a noção de tolerância trazida por Rawls (2000), primeiramente em $A$ Theory e sua relação direta com a noção de liberdade presente no primeiro princípio, mais especificamente sobre a liberdade de consciência igual, sem desconsiderar, também, que a ideia de tolerância também será objeto de investigação por Rawls em The Law of People, no qual é por meio do Princípio da Tolerância que o autor viabiliza a inserção, na segunda posição original, dos povos não liberais, mas decentes.

Antes de adentrarmos a problemática da tolerância a partir de Rawls, cabe fazer uma breve introdução sobre a temática. A Carta sobre a Tolerância, escrita por John Locke em 1689, é o marco sobre a discussão que envolve a problemática da separação das questões de ordem pública das questões de ordem religiosa, ou "a distinção entre a comunidade política e a sociedade religiosa, distinção e separação radical entre as funções da igreja e as do Estado". Aquele que governa, por Locke chamado de Magistrado, deve agir conforme as leis postas pelo Estado e tão somente ele possui em suas mãos o poder da força pública garantida pela lei. "A 
(RE)Pensando o espaço público democrático: o fato do pluralismo e a ideia de tolerância na concepção política de justiça de John Rawls

função da força pública é assegurar a paz para todos e a liberdade para cada um”, deixando claro, nesse contexto, que tem o dever e o poder de administrar a comunidade e garantir a ordem. (LOCKE, 1987, p. 48-49)

Diferentemente do papel do Estado, a Igreja, como "uma sociedade livre e voluntária" (LOCKE, 1987, p. 49), estaria diretamente ligada às manifestações de fé e adoração a Deus, cabendo a cada indivíduo escolher livremente a qual religião (crença) irá pertencer, posto que ela não possui o poder de impor, de forma coativa, tal condição. Ou seja, ela dispõe tão somente do "direito de discutir, de argumentar, de exortar; como sanção, o direito de excluir do seu seio os que considere em desacordo irredutível com ela." Por tais razões, Estado e Igreja possuem uma zona delimitada de atuação e "a tolerância é a conseqüência direta desta separação [...]" (LOCKE, 1987, p. 51).

É em razão desta constatação que Locke (1987, p. 51) denuncia todos os que "tomam a religião como pretexto para satisfazer o seu desejo de riqueza e de poder, ou até para dar livre curso ao seu fanatismo, corroído de vícios e crueldade. É este farisdísmo que está na origem dos piores excessos da intolerância”, ameaçando todos que, dispondo de um poder temporal, são tentados a dele abusar. Também, neste sentido,

A sua doutrina sobre a tolerância funda-se na distinção radical entre o domínio da
política e o da fé; as religiōes que infringem esta distinção não são puras religiões,
não têm o direito de obter os benefícios desta distinção que elas não respeitam; não
têm nenhum direito à tolerância e isto tanto menos quanto procuram ter influência
sobre o Estado. A condenação do catolicismo submetido ao Papado por laços
políticos, como a do ateísmo, fundamentalmente inadequado para manter os laços
morais necessários à vida política, mostram bem que a tolerância não está fundada
por Locke nos direitos da consciência, mas na defesa da liberdade essencial ao homem
e na salvaguarda da paz no Estado. Eis o seu princípio e o seu limite. (LOCKE, 1987,
p. 55)

Para Rawls (1999), por sua vez, a ideia de um Estado confessional estaria completamente superado na sua teoria; teria o governo apenas à obrigação de garantir e, também, limitar a liberdade religiosa e moral em condições iguais. Conforme o autor, a limitação da liberdade de consciência somente seria permitida quando houvesse a necessidade de restabelecimento da ordem pública, caso em que a justiça como equidade, enquanto concepção de justiça estaria ameaçada. Como argumenta o autor americano, a negação de liberdades iguais só seria permitida para evitar uma injustiça ou uma perda de liberdade em proporções maiores.

Diante de tais questões, Rawls nos desafia com dois questionamentos: 1) Como tolerar o intolerante? e, 2) O intolerante pode ter seu direito de liberdade reduzido? Diante dela, Rawls (2002, p. 239), explicita que "Conhecendo a estabilidade inerente a uma constituição justa, os 
membros de uma sociedade bem-ordenada confiam que só será preciso limitar a liberdade dos intolerantes em casos especiais, quando for necessário para preservar a própria liberdade igual. Nesse sentido, em síntese, para o autor a intolerância apenas seria tolerada até o ponto em que ela não afetasse a segurança da sociedade. ${ }^{6}$ Mais ainda, os direitos de liberdade, invioláveis até mesmo para os cidadãos que seguem doutrinas intolerantes, teria o seu valor reduzido ou limitado quando estivéssemos diante de um quadro de intolerância capaz de atingir significativamente a ordem social justa e democrática de uma sociedade. Rawls (1999) denomina essa atitude de "auto-preservação".

Para Rawls (2002), a posição original estabelece um pacto entre todos os cidadãos, definindo os termos de cooperação, pacto esse que poderá ser reavivado quando necessário, uma vez que os princípios representariam o alicerce da sociedade democrática bem ordenada. Como bem destaca Rawls (2002, p. 240), "As liberdades de alguns não são suprimidas simplesmente para possibilitar uma liberdade maior para outros. A justiça proíbe essa espécie de raciocínio em relação à liberdade, da mesma forma que o proíbe em relação à soma das vantagens". Seria, portanto, "apenas a liberdade do intolerante que deve ser limitada, e isso é feito para preservar a liberdade igual em uma constituição justa, cujos princípios os próprios intolerantes reconheceriam na posição original."

Nesse sentido, todas as vezes que houver dúvidas quanto às liberdades fundamentais, ou quando essas sofrerem qualquer ameaça a sua efetividade por parte de convicções morais abrangentes, o autor recomenda retomarmos a essência do contrato/pacto firmado entre os indivíduos, impresso nos princípios de justiça, a fim de promover a reconciliação necessária para garantir a harmonia e a cooperação social. (RAWLS, 1999)

É importante destacar que Rawls (2003, p. 45), evidencia que uma sociedade democrática e bem ordenada é plural, ou seja, a concepção política de justiça que afirma não exige que os cidadãos professem uma mesma concepção de bem. "O fato do pluralismo razoável implica que não existe doutrina, total ou parcialmente abrangente, com a qual todos os cidadãos concordem ou possam concordar para decidir as questões fundamentais de justiça política."

Ao assumir que "[...] o fato do pluralismo razoável é uma condição permanente de uma sociedade democrática," Rawls (2003, p. 47) também assume que essa não é uma condição temporária, mas é parte da cultura política pública das sociedades democráticas e, querendo ou

\footnotetext{
${ }^{6}$ Sobre até que ponto é possível tolerar o intolerante que está em Rawls para além das sociedades nacionais. Em O Direito dos Povos, o autor questiona-se sobre até que ponto povos liberais devem tolerar povos não liberais. A ideia de participação na Sociedade dos Povos está diretamente relacionada a essa questão. Não se exige que todos os povos sejam liberais, porém requer que sejam decentes.
} 
(RE)Pensando o espaço público democrático: o fato do pluralismo e a ideia de tolerância na concepção política de justiça de John Rawls

não, continuarão de geração em geração enquanto os indivíduos forem razoáveis e endossarem os princípios de justiça que alicerçam a proposta de justiça. Cabe destacar que, para Rawls o fato do pluralismo é um elemento limitador do que é possível tanto nas sociedades nacionais quanto na Sociedade dos Povos por parte de seus membros. Portanto, sua concepção política de justiça emerge como capaz de acolher essas várias concepções de bem que orbitam uma sociedade plural, estabelecendo um consenso entre elas capaz de possibilitar certa harmonia para a ordem pública.

Nesse sentido, é fundamental para que a estabilidade aconteça em uma sociedade plural, definir os termos que irão ser objeto de consenso entre os cidadãos. Esses termos devem versar, especificamente, sobre questões políticas, que não serviriam de objeto de desavenças entre os indivíduos e as mais diversas doutrinas morais que convivem no interior de uma sociedade. Para Rawls (2000, p. 183), "somente uma concepção política de justiça da qual se possa razoavelmente esperar que todos os cidadãos endossem pode servir de base à razão e a justificação pública.”

Não seria razoável utilizar o poder estatal para tentar impor uma única concepção do bem. Uma concepção somente seria razoável se conseguisse dialogar com as mais variadas concepções do bem e levasse em consideração determinados valores, que, para a justiça como equidade, são considerados fundamentais: liberdade civil, política, social, dignidade e respeito mútuo. Tais valores, presentes nos princípios de justiça, dariam as diretrizes para o estabelecimento de uma ordem justa e solidária.

De acordo com Audard (2006), os conceitos de vinculação, pertencimento e reconhecimento foram reformulados nos últimos tempos, afastando-se das concepções trazidas pelas teses comunitaristas e culturalistas. $\mathrm{O}$ fato do pluralismo e suas discussões no entorno das sociedades democráticas fez com que a demanda por reconhecimento se centrasse agora na individualidade, configurando novos grupos denominados de "grupos humanos", norteados por uma pluralidade de valores individuais e direitos, que são parte da sociedade complexa do século XXI.

Cabe destacar que a referida autora vai mais além nos seus posicionamentos a respeito do pluralismo em sociedades democráticas. Entende que várias foram às críticas comunitaristas nesse ponto, posto que "[...] defendem que a identidade coletiva é constitutiva da identidade moral individual.” (AUDARD, 2006, p. 133). Para a autora, isso

[...] nos leva a condições não democráticas de desenvolvimento. Eu diria, sobretudo, que quando as condições políticas mínimas da liberdade existem, o indivíduo poderá se diferenciar de maneira crítica e consciente. Ele é capaz de exercer escolhas, em certos limites, e certamente não é mais o resultado passivo de condições exteriores. 
Nem as culturas são mais entidades imutáveis, essenciais, mas estão sem parar em movimento e em interação, nem os indivíduos são mais, do mesmo modo, joguetes de condições exteriores. Tudo dependerá do papel exercido pelas instituições da liberdade a fim de que a atividade comunicacional da razão sirva de mediação eficaz e suscite um espaço público de discussão no qual um número cada vez maior de indivíduos são chamados a intervir e a se transformar eles próprios no contrato com os outros. (AUDARD, 2006, p. 133)

A autora citada anteriormente, diferentemente de Rawls, para quem a transformação social somente acontece por meio de um consenso em torno de princípios de justiça, acredita que a "ética pública não se deixa facilmente separar de suas raízes 'nos estilos de vida', nas escolhas existenciais ou ainda nas 'doutrinas abrangentes', não públicas que 'buscam fortemente a verdade' e dão sentido e valor às existências individuais.” (AUDARD, 2006, p. 140) Para tanto, a sua ética pública está pautada pelo "individualismo democrático", valores que pertencem a cada indivíduo. "A ideia de razão pública é, portanto, um componente essencial do que é preciso compreender por ética pública ${ }^{7}$ democrática [...]" Os embates ocorridos em torno de direitos fazem parte desse processo; "a discussão é parte essencial da legitimidade $[. .$.$] as razões de agir ou consentir não podem ser impostas do exterior, mas devem$ ser interiorizadas"; é uma relação de troca entre os valores que pretende preservar e as normas possíveis de garantir a efetividade da justiça. (AUDARD, 2006, p. 140)

Nesse ponto é possível observar mais uma divergência entre Audard (2006, p. 140) e Rawls, quando ela afirma ser muito "simplista assimilar a ética pública a uma 'teoria da justiça', como faz Rawls, ou seja, a um conjunto de princípios que regulam as relações sociais sem que seja necessário fundamentá-los em uma concepção partilhada da vida boa ou, melhor ainda, do ideal". Para Audard (2006, p. 140), essa posição de Rawls seria a de um 'consenso sobreposto' entre doutrinas abrangentes dos cidadãos, correspondendo tal distinção "mais ou menos àquela feita por Habermas entre normas e valores, entre o justo sobre o qual podemos entrar em acordo desde que adotemos um ponto de vista imparcial, e o 'bom' ou o desejável, que é o resultado da decisão e preferências pessoais."

Outro ponto de destaque, segundo Audard (2006), objeto de críticas a Rawls por parte de comunitaristas como Sandel, é a concepção de pessoa na teoria liberal. Sandel (2000) em sua obra tece críticas a Rawls relativas à posição original e aos indivíduos como sujeitos racionais e desinteressados, alheios aos percalços da vida em sociedade. A crítica do "eu desvinculado", desenvolvida por Sandel e direcionada a Rawls, também foi analisada por Forst (2010, p. 17-18), o qual afirma que, para Sandel, “[...] na base da teoria de Rawls reside uma

\footnotetext{
${ }^{7}$ No entendimento da autora, "[...] esse campo da ética pública é, antes de tudo, o da legislação e o de uma sociedade mais justa, e não de uma sociedade melhor em função de uma concepção pessoal de bem" Observamos, nesse ponto, uma certa vinculação aos ideais rawlsianos. (AUDARD, 2006, p. 140)
} 
(RE)Pensando o espaço público democrático: o fato do pluralismo e a ideia de tolerância na concepção política de justiça de John Rawls

'antropologia filosófica' que pode ser percebida na descrição das partes na 'posição original'”, o que o leva a lançar o argumento de que "Ralws, para justificar a 'posição original' no 'equilíbrio reflexivo', tem de fazer determinadas suposições antropológicas individualistas que legitimam a descrição das partes racionais”. Deste modo, sintetiza Forst (2010, p. 18), Sandel objetiva mostrar que o sujeito moral de Rawls seria “um 'eu desengajado' [unencumbered self], um eu 'desvinculado' que não faz jus à experiência ética de ser um eu. É um eu previamente individualizado, cuja identidade não está vinculada de modo constitutivo com seu meio ambiente, principalmente com outros sujeitos".

A partir de tais críticas, Audard (2006), entende que não é possível ver o indivíduo como um sujeito desvinculado da sua realidade social, separado de seus vínculos, atomizado, alheio ao contexto em que vive. No entendimento da autora (2006, p. 145), o "eu do liberalismo político de Rawls [...] não é 'desengajado', disponível a tudo ou indisponível a tudo e, portanto, nesse sentido, 'amoral"'. Muito pelo contrário; o indivíduo na proposta rawlsiana tem o "dever de civilidade" ${ }^{\prime}$, possuindo como referência o senso de justiça, o que o faz devedor de respeito aos outros. Todas as suas ações devem ser compatíveis com as dos demais indivíduos.

Deste modo, o consenso necessário para garantir a estabilidade na justiça como equidade não é um modus vivendi. ${ }^{9}$ Ele está muito além de ser um acordo individual ou entre grupos interessados em impor a sua visão abrangente. Concordar com uma concepção política de justiça não significa abrir mão das doutrinas morais abrangentes (religiosa, moral, filosófica...) que norteiam a vida pessoal de cada indivíduo. Tais doutrinas, na realidade, serão o ponto de partida para o endosso de uma concepção política pública de justiça, e o acordo se dará sobre os elementos constitucionais essenciais, fundamentais para manter a dignidade de todo e qualquer cidadão.

Teremos dois estágios relativos ao consenso entre os cidadãos de uma sociedade que pretenda ser bem ordenada e fundada a partir de uma teoria política de justiça. O primeiro deles é o estágio constitucional, quando a tolerância aparece como uma condição de possibilidade; o segundo é o consenso sobreposto, ocorre quando doutrinas morais abrangentes razoáveis divergentes endossam a mesma concepção política de justiça, obtendo um número significativo de adeptos e passando de geração em geração. (RAWLS, 2001)

\footnotetext{
${ }^{8}$ Esse dever de civilidade é um elemento que perpassa todo o projeto rawlsiano de justiça, desde A Theory (1999; 2002), passando por Political Liberalism (1993; 2011;2000) e chegando até The Law of People (2000, 2001).

${ }^{9} \mathrm{O}$ termo modus vivendi, empregado por Rawls, tem como principal objetivo demonstra a necessidade de estabilidade e que essa estabilidade não seja momentânea/passageira, um mero modus vivendi, mas que seja parte do objetivo de todas as sociedades. (grifo nosso) 
Cada cidadão terá a liberdade de escolher a doutrina moral abrangente que mais the agrada, ou que faça parte da história da sua vida, e relacionar tal concepção com a concepção política de justiça compartilhada na sociedade. Como a justiça como equidade, na condição de teoria, requer o endosso de elementos fundamentais para cada um dos cidadãos, no entender de Rawls (2001), não haverá tanta dificuldade em aceitá-la; diferente seria se estivesse o Estado a impor uma doutrina moral abrangente, oprimindo e fazendo uso da força para sua observância. Essa seria uma maneira equivocada de pensar a justiça como equidade para uma sociedade bem ordenada.

Procurar um equilíbrio entre as várias doutrinas morais abrangentes para definirmos os termos de cooperação, no entender do autor americano, seria agir de forma errada. Devemos estabelecer, primeiramente, os termos equitativos para a cooperação entre os cidadãos livres e iguais, sabendo que cada um deles afirma uma determinada concepção do bem, porém essa não seria objeto para o consenso entre os indivíduos, e sim a lista de bens primários que reflete os valores fundamentais de liberdade, justiça, igualdade e razão pública, denominados por Rawls de valores da justiça.

Em referência a J. S. Mill, Rawls (2003, p. 270), ressalta que,

[...] os valores característicos do político são valores muito elevados e, portanto, difíceis de considerar: esses valores governam a organização básica da vida social o próprio alicerce de nossa existência - e determinam os termos fundamentais da política e da cooperação social. Na justiça como eqüidade alguns valores elevados são os valores da justiça expressos pelos princípios de justiça para a estrutura básica: os valores de liberdade política e civil igual, de igualdade eqüitativa de oportunidades, reciprocidade econômica, bem como as bases sociais do auto-respeito dos cidadãos.

Ainda, segundo Rawls (2003, p. 273), “[...] não há motivos para que qualquer cidadão, ou associação de cidadãos, tenha o direito de usar do poder estatal para favorecer uma doutrina abrangente, ou para impor suas implicações aos demais". Se assim o fosse, estaríamos negando a proposta de justiça como equidade que requer na sua base, como um valor fundamental, a liberdade de consciência igual para todos os cidadãos.

\section{Conclusão}

Rawls (2001), ao elaborar uma comparação entre a ideia de tolerância e consenso sobreposto, destaca que a tolerância era inicialmente como um mero modus vivendi nas sociedades, principalmente quando essas estavam profundamente divididas pelas questões religiosas pós-Reforma, ${ }^{10}$ assim como o consenso sobreposto também poderia ter essa mesma

\footnotetext{
${ }^{10}$ Nesse ponto o autor está se referindo às tensões existentes a partir do século 16, entre católicos e protestantes, e "A descoberta de uma nova possibilidade social, a possibilidade de uma sociedade pluralista e democrática razoavelmente harmoniosa e
} 
(RE)Pensando o espaço público democrático: o fato do pluralismo e a ideia de tolerância na concepção política de justiça de John Rawls

conotação em um primeiro momento. Para a ideia de consenso sobreposto, porém, interessa ir mais além e assegurar a estabilidade e a durabilidade da sociedade bem ordenada para todos os cidadãos, livres e iguais, razoáveis e racionais. A estabilidade afirmaria a diferença entre um consenso sobreposto e um modus vivendi.

Assim sendo, percebemos que a noção de consenso sobreposto apenas é possível no interior de uma sociedade democrática. Fica superada, com a teoria rawlsiana, a viabilidade de um consenso ligado à ideia de comunidade política tão recorrente nos discursos atuais. Nessa, existiria espaço apenas para o princípio da tolerância, posto que o consenso sobreposto exige uma concepção política de justiça firmada e reafirmada por todos os cidadãos, mesmo que essa afirmação parta de suas próprias visões de mundo. O que importa para a estabilidade da sociedade democrática e bem ordenada é que a mesma concepção de justiça seja endossada por todos os cidadãos e que um bem da própria sociedade floresça com o intuito de unir a todos em torno de um projeto de justiça igualitária.

\section{Referências}

AUDARD, Catherine. Cidadania e democracia deliberativa. Tradução de Walter Valdevino. Porto Alegre: EDIPUCRS, 2006.

FORST, Rainer. Contextos de Justiça: filosofia política para além de liberalismo e comunitarismo. Tradução de Denilson Luís Werle. São Paulo: Boitempo, 2010.

LOCKE, John. Carta sobre a Tolerância. Tradução de João da Silva Gama. Lisboa: Edições $70,1987$.

LOVETT, Frank. Uma teoria da justiça de John Rawls. Guia de leitura. Tradução de Vinícius Figueira. Porto Alegre: Penso, 2013.

RAWLS, John. A Theory of Justice. Revised Edition. Cambridge, Massachusetts: Harvard University Press, 1999.

RAWLS, John. Uma teoria da justiça. Tradução de Almiro Pisetta e Lenita M. R. Esteves. São Paulo: Martins Fontes, 2002.

RAWLS, John. Justice as fairness: a restatement. Cambridge, Mass: Harvard University Press, 2001.

estável, [decorrente] do sucesso das instituições liberais. Antes da prática bem-sucedida da tolerância em sociedades com instituições liberais não havia meio de conhecer essa possibilidade. Era mais natural acreditar, como pareciam confiar séculos de aceitação da intolerância, que a unidade social e a concórdia exigiam um acordo em torno de uma doutrina religiosa, filosófica ou moral geral e abrangente. A intolerância era vista como condição da ordem e da estabilidade social. O enfraquecimento dessa crença ajuda a abrir caminho para instituições livres"

222

Prisma Jur., São Paulo, v. 18, n. 2, p. 208-223, jul./dez. 2019 
RAWLS, John. Justiça como equidade: uma reformulação. Tradução de Claudia Berliner; rev. técnica Álvaro De Vita. São Paulo: Martins Fontes, 2003.

RAWLS, John.. Political Liberalism. New York: Columbia University Press 1993.

RAWLS, John. O liberalismo político. Edição ampliada. Tradução de Álvaro de Vita. São Paulo: Martins Fontes, 2011.

RAWLS, John. O liberalismo político. Tradução de Dinah de Abreu Azevedo. 2. ed. São Paulo: Ática, 2000.

RAWLS, John. The Law of Peoples; With the idea of Public Reason Revised. Second printing. Harvard University Press, 2000.

RAWLS, John. O Direito dos Povos. Tradução de Luís Carlos Borges. São Paulo: Martins Fontes, 2001.

RICOEUR, Paul. O justo ou a essência da justiça. Tradução de Vasco Casimiro. Lisboa: Instituto Piaget, 1995.

RIVERA, Faviola. Rawls, FIlosofía y Tolerancia. In: Isonomia. Revista de Teoría y Filosofía del Derecho. N ${ }^{\circ}$ 19, Octubre 2003.

SÁ, Alexandre Franco de. O problema da Tolerância na Filosofia Política de John Rawls. Covilhã, Portugal: Universidade da Beira do Interior, 2008. (Coleção LusoSofia)

SANDEL, Michael J. El Liberalismo y los limites de la Justicia. Tradução de María Luz Melon. Barcelona: Gedisa, 2000.

WEBER, Thadeu. A ideia de um "mínimo existencial" de J. Rawls. kriterion, Belo Horizonte, no 127, Jun./2013, p. 197-210.

Recebido em 08 jul. 2019 / Aprovado em 13 dez. 2019

Para referenciar este texto:

ZEIFERT, Anna Paula Bagetti; NIELSSON, Joice Graciele. (Re)pensando o espaço público democrático: o fato do pluralismo e a ideia de tolerância na concepção política de justiça de John Rawls. Prisma Jurídico, São Paulo, v. 18, n. 2, p. 208-223, jul./dez. 2019. https://doi.org/10.5585/PrismaJ.v18n2.14395. 